\title{
ESTIMATION OF ROCKFALL HAZARD USING A GIS-BASED THREE-DIMENSIONAL ROCKFALL SIMULATION MODEL
}

\author{
Charalambous S. ${ }^{1}$, and Sakellariou M. ${ }^{1}$ \\ ${ }^{1}$ National Technical University of Athens, School of Rural and Surveying Engineering, Laboratory \\ of Structural Mechanics,stefanos@survey.ntua.gr,mgsakel@mail.ntua.gr
}

\begin{abstract}
Rockfall is a very common geomorphological process, yet a major hazard mainly in mountainous areas or along man-made slopes, potentially threatening lives, settlements, equipment, facilities and road infrastructure. In Greece, rockfalls are considered to be one of the most common forms of landslide as well as the most common failure mode likely to be triggered by a seismic event. Rockfall hazard assessment is requisite for both safety purposes (countermeasure design), as well as for land planning purposes. In this paper, a new three-dimensional rockfall simulation model, developed in GIS environment, is proposed as a tool for assessing rockfall hazard for a local-or even a regional-scale area. The application provides stochastic analysis, three-dimensional visualization and animation of rockfalls, by taking advantage of the capabilities offered by GIS. By means of case studies we evaluate the simulation model as a tool assisting spatial analysis and planning, which can be used in decision-making and design concerning road infrastructures, or even a large technical work, such as a dam.
\end{abstract}

Key words: Landslides, Stochastic modelling, Visualization.

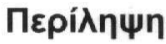

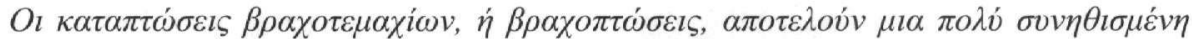

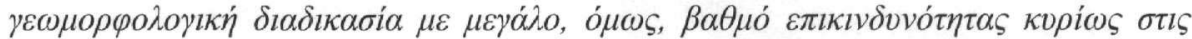

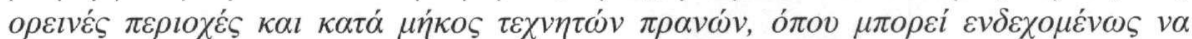

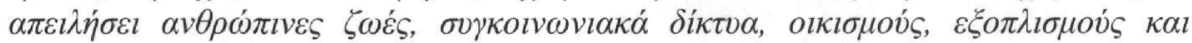

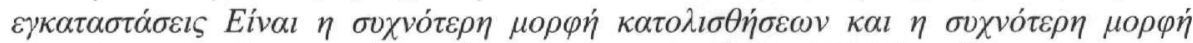

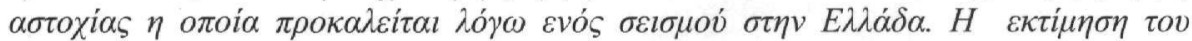

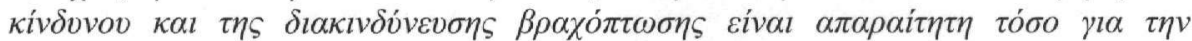

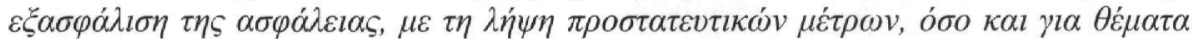

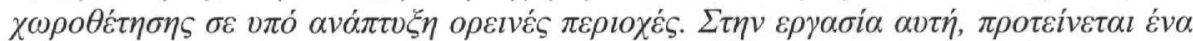

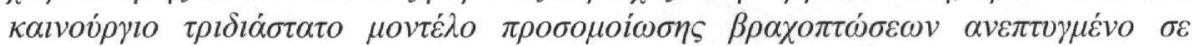

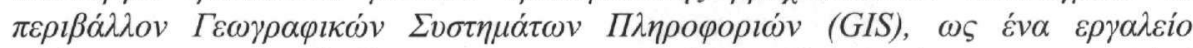

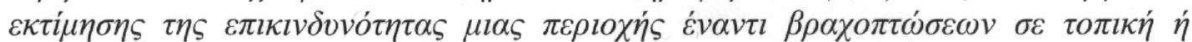

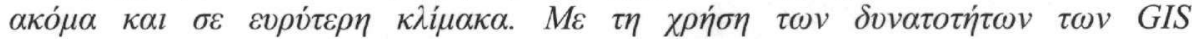

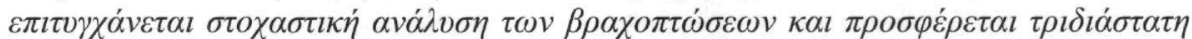

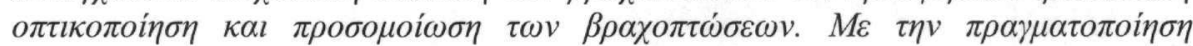

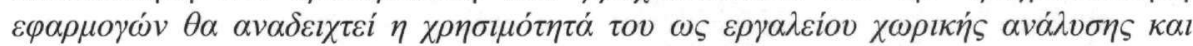

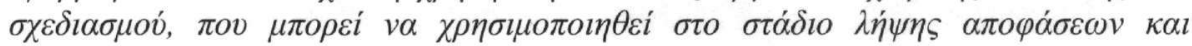




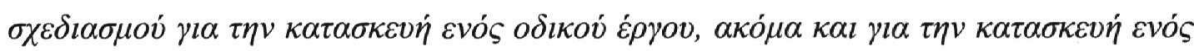

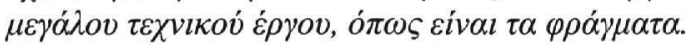

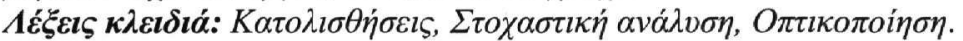

\section{Introduction}

\subsection{Rockfalls}

Rockfall is a very common-place geomorphological process. A number of rock fragments, ranging from small cobbles to large boulder hundreds of cubic metres in size, is detached by sliding, toppling or falling, falls along a vertical or sub-vertical cliff, proceeds downslope by bouncing and flying along ballistic trajectories or by rolling on talus or debris slopes (Varnes 1978), with speeds ranging from few to tens of metres per second. When the block has lost enough energy in impacts or by friction it stops on or at the foot of the slope.

As simple as it may seems, the phenomenon of rockfall has characteristics that renders it a hazard process and a major cause of landslides. The high energy, mobility, spatial and temporal recurrence are the characteristics that make rockfalls one of the most important natural hazards worldwide, mainly affecting mountainous areas and man-made slopes. They can threaten lives, roadways, settlements and facilities having tremendous consequences. In Greece, rockfalls are one of the most common forms of landslide as well as the most common failure mode likely to be triggered by a seismic event (Koukis 1988). Badger and Lowell (1992) stated that "A significant number of accidents and nearly a half dozen fatalities have occurred because of rockfalls in the last 30 years ... and ... 45 percent of all unstable slope problems are rockfall related".

Rockfalls are generally triggered by some climatic or biological event that changes the dynamic state of the rock block. Pore pressure increases due to rainfall infiltration, erosion of surrounding material during heavy rain storms, freeze-thaw processes in cold climates, chemical degradation or weathering of the rock, root growth or leverage by roots moving in high winds are such events. According to Hoek (1998), in an active construction environment, the potential for mechanical initiation of a rockfall will probably be one or two orders of magnitude higher than the climatic and biological initiating events described above.

Rochet (1987) has classified rockfalls into four categories, depending on the volume of rock mass involved in the rockfall, namely: single block falls (volume between $\left.10^{-2}-10^{2} \mathrm{~m}^{3}\right)$; mass falls $\left(10^{2}\right.$ $\left.10^{5} \mathrm{~m}^{3}\right)$; very large mass falls $\left(10^{5}-10^{7} \mathrm{~m}^{3}\right)$ and mass displacement $\left(>10^{7} \mathrm{~m}^{3}\right)$. Even when involving limited volumes, as in the first two categories, rockfalls may have high energy and mobility, making them greatly dangerous and destructive (Agliardi and Crosta 2003).

After a rockfall is triggered, the trajectory that rock blocks follow is the combination of four main processes, namely: sliding and/or toppling, free falling, bouncing (impact) and rolling, where impact is considered as the most complex, uncertain and poorly understood stage of a rockfall (Broili 1973). All these processes depend on laws of mechanics and a model used to describe rockfall trajectory can have various levels of complexity.

The most important factor controlling rockfall trajectory is the slope geometry. Slopes acting as 'skijumps' are the most dangerous as they impart a high horizontal velocity to the falling rock, causing it to bounce a long way out from the toe of the slope. Another equally significant factor is the slope material properties. Clean faces of hard unweathered rock are very dangerous because they do not retard the movement of the falling or rolling rock to any significant degree. On the other hand, surfaces covered in talus material, scree or gravel absorb a considerable amount of the energy of the falling rock and, in many cases, will stop it completely. Other factors such as the size and shape of the rock boulders, the coefficients of friction of the rock surfaces and whether or not the rock breaks into smaller pieces on impact are all of lesser significance (Hoek 1998). 


\subsection{Geographical Information Systems}

Geographical Information Systems (GIS) contribute greatly in risk zonation mapping (Burrough and McDonnel 1998). Over the last decade, the widespread availability of GIS has given engineers the opportunity to conduct landslide hazard assessments over large areas by the use of simplified geotechnical models. One of the main advantages that GIS offer is the development of hazard occurrence models, e.g. rockfall hazard simulation models, permitting evaluation of results and adjustment of the input variables (Sakellariou and Ferentinou 2001, Ferentinou 2004, Sakellariou et al. 2006). GIS allow management and analysis of large amounts of spatial data and support the zonation of large-scale territories, such as an entire province or a river basin. However, they are not a panacea because the generalization of terrain properties over large areas can lead to errors in stability evaluation. Such errors are only acceptable in screening level applications as well as in a preliminary study used to identify areas that require a more detailed analysis.

\section{Rockfall Modelling}

Rockfall hazard assessment is essential for both land planning purposes and the design of countermeasures (e.g. the design of slope benching, retaining fences, fills, ditches and berms, rock sheds and tunnels). Modelling rockfalls is considered as a very effective way to achieve this as it aims to assess, among others, the envelope of trajectories, the maximum runout distance, the distribution of kinematic parameters along a fall path and the probability for a specified "design block" to stop at specific distances from the starting point (Agliardi and Crosta 2003).

At first glance a rockfall is a simple process to model. However, a rockfall represents an example of a relatively simple mechanical system whose behaviour cannot be predicted in space and time, even if the initial conditions and the driving force (i.e. gravity) are known (Guzzetti et al. 2002). The parameters that control a rockfall trajectory, i.e. the location of the source area (starting point), the shape and geometry of the boulder, the mechanical properties of the rock and the slope, and the topography (Ritchie 1963) are difficult to be precisely determined as they vary widely. Thus, rockfall behaviour can be various and complex and predicting the trajectory of a rockfall is a complicated operation.

An effective way to deal with this uncertainty, is to perform stochastic analysis by varying the parameters incorporated into the model (e.g. mass, shape, size, coefficient of restitution, friction, etc.) according to different probability density distributions (uniform, normal, exponential, etc.), as well as by launching numerous blocks from each source area. A great number of rockfall models include a Monte Carlo simulation technique to vary the parameters included in the analysis.

Numerical modelling of rockfalls is quite sensitive to the physical-mechanical parameters and the morphological description. The most crucial part in describing a rockfall trajectory using a mathematical model, also defining its reliability to a large extent, is finding the right amount of energy lost by rock blocks during the impact with the ground as well as the direction they will follow afterwards. As for the former, finding the right amount of energy lost is a very difficult task because the relationships linking the energy loss to different variables (e.g. the roughness and the geotechnical properties of the slope, the shape and dynamics of the block) are not clearly defined.

In most cases, all the effects due to plastic deformation of substratum and the geometric configuration of impact are taken in account by "contact functions" relating the kinematics of the block (in terms of velocity) or its dynamics (in terms of energy) before and after the impact (Agliardi and Crosta 2003). Such functions are expressed as restitution and friction coefficients, usually regarded as material constants. Pfeiffer and Bowen (1989), Jones et al. (2002) and Chau et al. (2002) have developed scaling functions relating the restitution coefficients to the impact velocity, but they are empirical and based on specific datasets obtained by in-situ tests performed in different conditions (Agliardi and Crosta 2003), thus, they cannot be used in different areas or 
conditions. The procedure recommended is estimating the values of restitution coefficients from in-situ tests carried out in the area under investigation.

Although a two-dimensional (2D) approach is favored from an operational and computational point of view, the interpretation of the results and their extension to neighbouring areas is subjective (Crosta and Locatelli 1999), due to the fact that the 2D simulation of rockfalls is executed along user-specified pre-defined slope profiles neglecting the three-dimensional effect of the topography, which plays a major role in controlling the dynamics of falling blocks. This is a severe limitation particularly along steep channels, where the topography is concave (i.e., a hollow, a couloir) or convex (i.e., a fan), at the apex of a fan, or in any other area where minor changes in topography influence a rockfall trajectory (Crosta and Locatelli 1999).

Three-dimensional rockfall (3D) simulation models prevail over 2D models in the way they model rockfalls as they take into account the $3 \mathrm{D}$ effect of topography on rockfall trajectories. The most important 3D effect is the "lateral dispersion" of rockfall trajectories, largely affecting the way we model rockfall dynamics, design countermeasures and assess rockfall hazard (Crosta and Agliardi 2004). Lateral dispersion is the ratio of the lateral distance separating the extreme fall paths to the slope length (Azzoni et al. 1995) and can be represented through a "shadow cone" with the apex placed at the rockfall source area. The occurrence of lateral dispersion makes it difficult to choose a priori the right rockfall path when a 2D approach is adopted (Agliardi and Crosta 2003).

\section{Proposed Three-Dimensional Rockfall Simulation Model}

In the beginning of 2006 a new 3D rockfall simulation model was developed (Charalambous 2006) and it has been continuously upgraded since. In its latest version, the model can simulate numerous spatially distributed 3D rockfall trajectories adopting a kinematic approach. The new 3D rockfall simulation model is implemented in an application, called ROCKFALL ANALYSIS, which runs in the environment of the ArcGIS software exploiting the vast and powerful capabilities that GIS offer. ROCKFALL ANALYSIS provides both 2D and 3D representation of rockfall trajectories, and furthermore, the 3D animation of rockfalls, which shows rockfalls as they would have occurred in real time, as well as statistic tools for analyzing the rockfall.

\subsection{Assumptions}

The proposed 3D rockfall simulation model is characterised by the following assumptions:

- The model deals only with the first two types of rockfalls (Rochet's classification), i.e. single block falls and mass falls, also called "fragmental rockfalls" (Evans and Hungr 1993), where the interaction among the falling blocks is null or negligible.

- A kinematic approach, treating the falling block as a lumped mass (i.e. a point mass), allows to model free fall, bouncing/impact, rolling and sliding motions in a 3D framework. The influences of the shape, the size and the angular momentum of the rock boulder on the rockfall trajectory are only taken into consideration when rolling occurs. While in air, a boulder's velocity is considered only translational, i.e. rotational velocity is ignored.

- Topography is represented by a Digital Terrain Model (DTM) in Triangulated Irregular Network (TIN) format, without resolution restrictions. In that way, 3D topography and, therefore, the lateral dispersion are taken into account.

- A number of input data (e.g. frictional characteristics, restitution coefficients) are spatially distributed within the study area, in ESRI shapefile format.

- Rockfall sources can be defined as points, polylines, polygons, rectangles, circles or ellipses. When the source area is a point, the point selection can be made either in $2 \mathrm{D}$ or in $3 \mathrm{D}$ environment. The latter is recommended as it helps in a better and more sophisticated selection of the point since the $3 \mathrm{D}$ visualization contributes in a better understanding of the 
area's topography. When the source area is defined by a polyline or a surface, equally distributed points are generated upon the polyline or within the surface, in a grid-like distribution, depending on the resolution selected. A user-specified number of rock boulders can be thrown from a randomized selected subset of the generated points. In that way stochastic modelling can be performed. For the moment, the source area (initial position of rocks) is the only parameter defined as a random variable. The other input parameters can be defined only by constant values.

- Air drag and block fracturing are not taken into account.

\subsection{Input Data}

In order to run rockfall simulations the model requires the following input data:

- The TIN representing the 3D topography of the study area.

- A polygon shapefile containing the frictional characteristics of the ground (friction angle of the geological formations).

- A polygon shapefile containing the normal and tangential restitution coefficients (in terms of velocity) on the block velocity.

- The rockfalls source area, defined using the ways aforementioned.

- The magnitude and direction of the initial velocity.

- The magnitude of the velocity, which defines the transition point between the projectile state and the state where the rock is moving too slowly to be considered a projectile and should instead, be considered rolling, sliding or stopped. The velocity with this magnitude is called minimum velocity.

- The model also allows the design and implementation of barriers (3D polygon shapefile), vertical or non-vertical, as a remedial measure. The model calculates the rockfall trajectory depending on the characteristics of the barrier, like its location, geometry (inclination, orientation and height), frictional characteristics and restitution coefficients.

\subsection{Output Data}

The results of the proposed rockfall simulation model are in spatial form. Three-dimensional data are produced, but in order to enhance the information generated, qualitative data are also produced referenced to the output spatial data. Specifically, the output data are:

- A 3D point shapefile containing all the points calculated which form the rockfall trajectory. For each point a number of data are provided into the shapefile's Attribute Table, namely: the Code name (Id) of the rockfall in which the point belongs, the location (X,Y,Z) of the rock boulder, the velocity $\left(\mathrm{V}_{\mathrm{x}}, \mathrm{V}_{\mathrm{y}}, \mathrm{V}_{\mathrm{z}}\right)$ at that location, the time passed since the initiation of the rockfall, the aspect (aspect is the dip direction of the Tin triangle), the slope, the friction angle and the restitution coefficients of the underlying slope and comments for the present state of the boulder.

- A 3D polyline shapefile containing all the rockfalls simulated. The length and time of each rockfall are given in the attribute table.

- Tables with statistics for each rockfall (e.g. total horizontal and vertical movement, total duration and length, maximum velocity and height DZ above ground) or for the whole set of the rockfalls (e.g. minimum and maximum length, duration and DZ).

- A 3D polygon shapefile with the subarea subjected to the simulated rockfalls. This subarea is composed by the Tin triangles traversed by the rockfalls. Data concerning the number of rockfalls traversing each triangle, the maximum velocity and the maximum height above 
ground surface that characterize the set of the rockfalls traversing each triangle are provided.

- A 3D real time animation of the simulated rockfalls.

\subsection{The Kinematical Approach}

\subsubsection{Initial Conditions}

Each rockfall starts from a point $\left(X_{0}, Y_{0}, Z_{0}\right)$ either upon or above the ground surface. The initial velocity $\overrightarrow{V_{0}}$ of the rock boulder is considered translational and it is described by three parameters, namely: the magnitude $\left(V_{0}\right)$, the angle $\alpha_{0}$, the angle formed by velocity $\overrightarrow{V_{0}}$ and the horizontal plane $\mathrm{XY}$, and the angle $\theta_{0}$, which is the angle formed by the projection of velocity $\overrightarrow{V_{0}}$ on XY plane and the $\mathrm{X}$ axis. The angle $\theta_{0}$ represents the orientation of the velocity $\vec{V}_{0}$. Besides the initial velocity we also have the minimum velocity $V_{\min }$. We note that rockfall assessment includes seismic hazard assessment also when rockfalls are set to start with an initial velocity greater than zero.

\subsubsection{Bouncing / Impact}

During bouncing the rock boulder has a velocity with such a magnitude that will move it, through the air, from its present location to a new location where it will strike the ground surface. The path the rock will take through the air is, because of the force of gravity, a parabola and during this parabolic movement the place where the rock boulder will hit the ground is the intersection of its trajectory, as it is described by simple laws of mechanics, and the DTM of the study area.

Impact is considered the most complex, uncertain, and poorly understood process of a rockfall. In the proposed simulation model, the impact is considered partially elastic, depending on the mechanical properties of the ground, i.e. the restitution coefficients. The most common definitions of restitution coefficients are used (tangential $\left(R_{\mathrm{t}}\right)$ and normal $\left(R_{\mathrm{n}}\right)$ restitution coefficients).

At impact, considered instantaneous for sake of simplicity, energy is lost and the direction of motion of the rockfall changes depending on the slope's 3D geometrical (slope and aspect) and mechanical properties $\left(R_{\mathrm{t}}, R_{\mathrm{n}}\right)$.

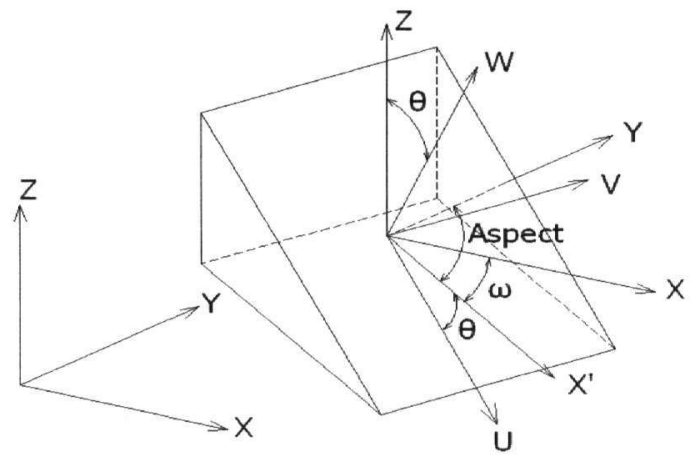

Figure 1 - The two reference coordinate Cartesian systems of the rockfall simulation model: the "Global" coordinate system (XYZ) and the "Local" coordinate system (UVW), and the relationship between them (Charalambous 2006)

The procedure adopted by the simulation model for calculating the post-impact velocity includes four stages:

1. Calculation of impact point $\left(X_{\text {imp }}, Y_{\text {imp }}, Z_{\text {imp }}\right)$ and the impact velocity ( $\left.V_{X i m p}, V_{Y \text { imp }}, \mathrm{V}_{Z \text { imp }}\right)$.

2. Transformation of the impact velocity from the Global Coordinate Cartesian System XYZ to a Local Coordinate Cartesian System, $\left(V_{U_{-} \text {before, }} V_{V_{\text {b before }},} \mathrm{V}_{W_{-} \text {before }}\right)$. If we use a Cartesian 
System UVW (Fig. 1) local to each TIN triangle (each triangle represents a slope), defined by the impact point as the point of origin, the axis $U$ tangential to the slope and towards the steepest downslope direction, the axis $\mathrm{W}$ perpendicular to the slope and the axis $\mathrm{V}$ tangential to the slope, then the velocity in the UVW Cartesian system is calculated using Equation 1. The transformation (Equation 2) involves two rotations (Fig. 2): a rotation of the Cartesian System XYZ about $Z$ axis for an angle $\omega=$ Aspect -90 and a rotation of the previously transformed system about $\mathrm{V}$ axis for an angle $\theta=$ Slope Angle.

Equation 1 - The transformation of the velocity from the Global to the Local Cartesian system UVW

$\left(\begin{array}{l}V_{U} \\ V_{V} \\ V_{W}\end{array}\right)=[R] \cdot\left(\begin{array}{c}V_{X} \\ V_{Y} \\ V_{Z}\end{array}\right)$, where $[R]$ is defined by equation 2.

Equation 2 - The transformation matrix from the Global to the Local Cartesian system UVW

$$
[R]=\left(\begin{array}{ccc}
\cos (\theta) \cdot \cos (\omega) & \cos (\theta) \cdot \sin (\omega) & -\sin (\theta) \\
-\sin (\omega) & \cos (\omega) & 0 \\
\sin (\theta) \cdot \cos (\omega) & \sin (\theta) \cdot \sin (\omega) & \cos (\theta)
\end{array}\right)
$$

3. Reduction of the impact velocity, referenced to UVW Cartesian System, according to the restitution coefficients. This is accomplished by the use of Equation 3.

Equation 3 - The reduction of the impact velocity due to the impact with the ground

$$
\left(\begin{array}{l}
V_{U_{-} \text {after }} \\
V_{V_{-} \text {after }} \\
V_{W_{-} \text {after }}
\end{array}\right)=\left(\begin{array}{c}
R_{t} \\
R_{t} \\
R_{n}
\end{array}\right) \cdot\left(\begin{array}{l}
V_{U_{-} \text {before }} \\
V_{V_{-} \text {before }} \\
V_{W_{-} \text {before }}
\end{array}\right)
$$

4. Transformation of the post-impact velocity $\vec{V}_{\text {afier }}$ back to the Global Coordinate Cartesian system XYZ by using equation 4 .

Equation 4 - The post-impact velocity referenced to the Glocal Cartesian system XYZ

$$
\left(\begin{array}{l}
V_{X_{-} \text {new }} \\
V_{Y_{-} \text {new }} \\
V_{Z_{-} \text {new }}
\end{array}\right)=[R]^{-1} \cdot\left(\begin{array}{l}
V_{U_{-} \text {after }} \\
V_{V_{-} \text {after }} \\
V_{W_{-} \text {after }}
\end{array}\right)
$$

After calculating the post-impact $\overline{V_{\text {new }}}$, the normal to the slope component of the post-impact velocity, $V_{\mathrm{W}_{-} \text {after, }}$, is then compared to $V_{\min }$. If $V_{\mathrm{W} \_ \text {after }}>V_{\min }$ then the bouncing continues but if $V_{\mathrm{W}_{-} \text {after }}<V_{\min }$ then the rock boulder spots bouncing and starts rolling or sliding along the slope's steepest path.

\subsubsection{Sliding or Rolling}

Whether the movement is sliding or rolling is determined by the ground's friction coefficient and the slope angle. Taken that rock boulders have circular shape (radius $\mathrm{R}$ and mass $\mathrm{m}$ ) then rolling occurs when slope angle $\theta$ is smaller than $\theta_{\max }=\operatorname{Arctan}\left(7 / 2 \cdot \mu_{s}\right)$, where $\mu_{\mathrm{s}}=$ friction coefficient. When the slope angle $\theta$ is greater than $\theta_{\max }$ then the movement taken place is sliding. 
The influence of rolling or sliding on the simulation model is expressed by the constant $K$ (Hoek 1987) used in equation for the calculation of the exit velocity, $V_{E X I T}=\sqrt{V_{0 U V}-2 \cdot s \cdot g \cdot K}$, where $V_{\text {OUV }}=$ the initial velocity of the rock tangential to the segment, $s=$ is the distance from the initial location to the endpoint of the segment towards the slope's steepest direction and $g=$ is the acceleration due to gravity. When the assumed condition is pure sliding then $K= \pm \sin \theta-\cos \theta \cdot \tan \phi$, where $\varphi=$ the friction angle, and when the assumed condition is a rolling sphere then $K= \pm(5 / 7) \cdot \sin \theta$. The symbol \pm is + if the initial velocity is downslope or zero and - if the initial velocity is upslope.

The simulation model has the great advantage of including the case where a rock boulder rolls/slides along a $\mathrm{V}$ shaped concave surface. While in other simulation models this would cause them to enter an endless calculation loop, and "crash" (to deal with such a problem, the models would take countermeasures (e.g. give each rock a certain amount of real time to finish all of its calculations had to be taken)), this does not occur in the proposed model, in which a rockfall simulation stops only due to reasons regarding the phenomenon of rockfalls.

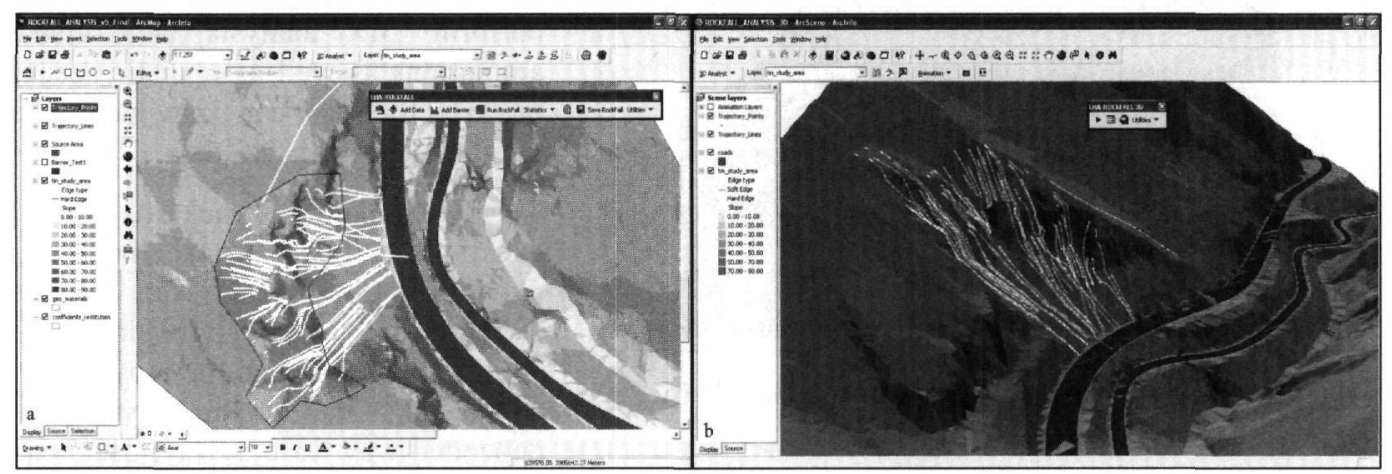

Figure 2 - a. The first section of ROCKFALL ANALYSIS running in ArcMap. b. The second section of ROCKFALL ANALYSIS running in ArcScene

\section{Implementation of the Rockfall Simulation Model in a GIS Environment - The Application "Rockfall Analysis"}

The simulation model is implemented in an application called ROCKFALL ANALYSIS developed in the environment of the GIS software ArcGIS. The application is written in VBA and is comprised by two basic sections:

- The first section, called "ROCKFALL_ANALYSIS.mxd," runs within the program ArcMap (Fig. 2a) and it is responsible for calculating the rockfall trajectories, according to the input data, and the $2 \mathrm{D}$ representation (plan view) of the simulated rockfalls. It contains all the output data, spatial or not. The spatial data, though in three-dimensions, in ArcMap are represented in $2 \mathrm{D}$.

- The second section, called "ROCKFALL_ANALYSIS_3D.sxd," runs within the program ArcScene (Fig. 2b) and it is responsible for the 3D visualization and animation of the simulated rockfalls and the $3 \mathrm{D}$ representation of the other output spatial data. It also contains the non-spatial data.

ROCKFALL ANALYSIS runs in each section by the use of the toolbarsvast created (Figure 2a,b). Apart from the functions that the application offers, a whole range of other useful functions are offered to users (e.g. mapping, analysis, exporting, printing, etc.) by the programs ArcMap and ArcScene, assisting in achieving a more integrated and credible rockfall hazard assessment. 
The most important algorithm of the application is the one used for the calculation of the rockfall trajectories since it determines the accuracy of the proposed rockfall simulation model. This algorithm is divided into five different algorithms, namely: the main algorithm, the projectile (the parabolic movement of rock boulder through air) algorithm, the impact (transformation of the impact velocity) algorithm, the free fall algorithm and the rolling/sliding algorithm. The main algorithm handles the calculation of the rockfall trajectories, as it sets up all of the initial conditions in preparation for the projectile, or free fall when needed, impact and rolling/sliding algorithms.

\subsection{Three-Dimensional Visualization}

Once the rockfall trajectories are calculated, an effective way of representing the rockfalls is in three dimensions (Fig. 2b). This capability is offered by the use of the second section of the

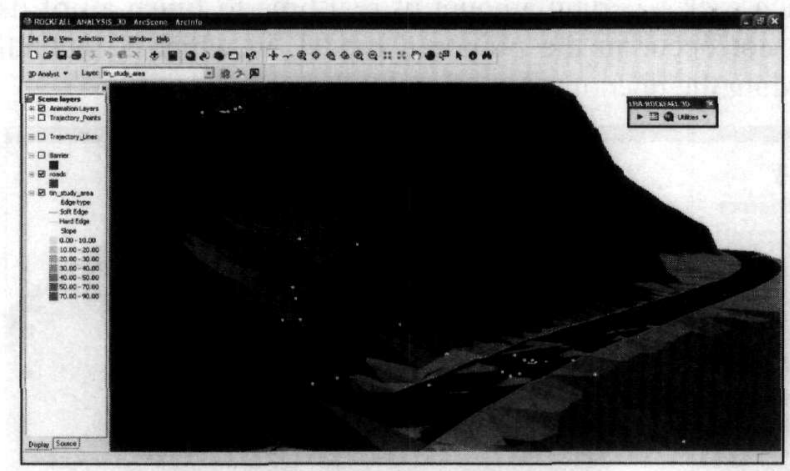

Figure 3 - The 3D animation of rockfalls in ROCKFALL ANALYSIS application, running in ArcScene environment, a specialized 3D viewing application. ArcScene allows you to manage your 3D GIS data, perform $3 \mathrm{D}$ analysis and make animations as well as realistic scenes in which you can navigate and interact with your GIS data.

The 3D animation of rockfalls (Fig. 3) offers the best way of visualizing this phenomenon. Users can create animations where rock boulders are shown to fall along the trajectories calculated, in a strongly timedepended way. In this way, users can have a very good perspective of rockfalls, they can fully comprehend what happens since they see the rockfalls as they would have occurred in reality, and they can take all the necessary countermeasures then. Furthermore, the 3D animations can be exported as videos for further use and study.

\subsection{Barriers}

Barriers in ROCKFALL ANALYSIS have the same influence on rockfalls as any other slope. Barriers must be created within the application and, once they are, they can be loaded at any simulation. Barriers have the same set of material properties $\left(R_{\mathrm{t}}, R_{\mathrm{n}}, \varphi\right)$ and geometrical properties (Aspect, Slope, Height) as the slopes (TIN Triangles), and that make them act like slopes during the rockfall simulations. Both vertical and inclined barriers can be created; this is an important capability that broadens the options given to engineers in order to design as more effective remedial measures as possible.

The simulation of remedial measures, such as a barrier, is useful to engineers because it allows them to test their design with more simulations. For example, a barrier proposed as a countermeasure could be placed in the simulation and then its effectiveness could be evaluated (Fig. 4). By executing numerous rockfall simulations and varying the barrier's design parameters, its adequacy can be evaluated leading to the best possible design.

\subsection{ROCKFALL ANALYSIS assists in Land Planning, the Design of Technical Works and in Safety Issues}

Rockfall hazard assessment is essential when dealing with land planning or the design of technical works (roads, dams, etc.) and infrastructure in mountainous areas. ROCKFALL ANALYSIS can strongly support rockfall hazard assessment when reliable and accurate input data are used. For 
example, the representation of rockfalls, especially in 3D, assists engineers to estimate rockfall hazard throughout the study area and decide where is the optimum place for a technical work, an infrastructure or a facility to be built. Furthermore, via the use of barriers, the best possible countermeasures can be obtained when protection of roads or settlements is required.

In order to extent the capabilities offered, ROCKFALL ANALYSIS provides additional tools for the study of rockfalls in a more quantitative way. The tool "Symbolize Velocity" symbolizes the simulated rockfalls based on the magnitude of the velocity along their trajectory (Fig. 5a). In that way, engineers know, for example, where rock boulders have their maximum velocity thus where the rockfalls are more dangerous.

Another tool shows the subarea within the study area that was subjected to the simulated rockfalls (Fig. 5b). This area is formed by the Tin triangles traversed by the rockfalls and data referred to the amount of rockfalls traversing each triangle, the maximum velocity and the maximum height above ground surface of the set of rockfalls traversing each triangle are provided.

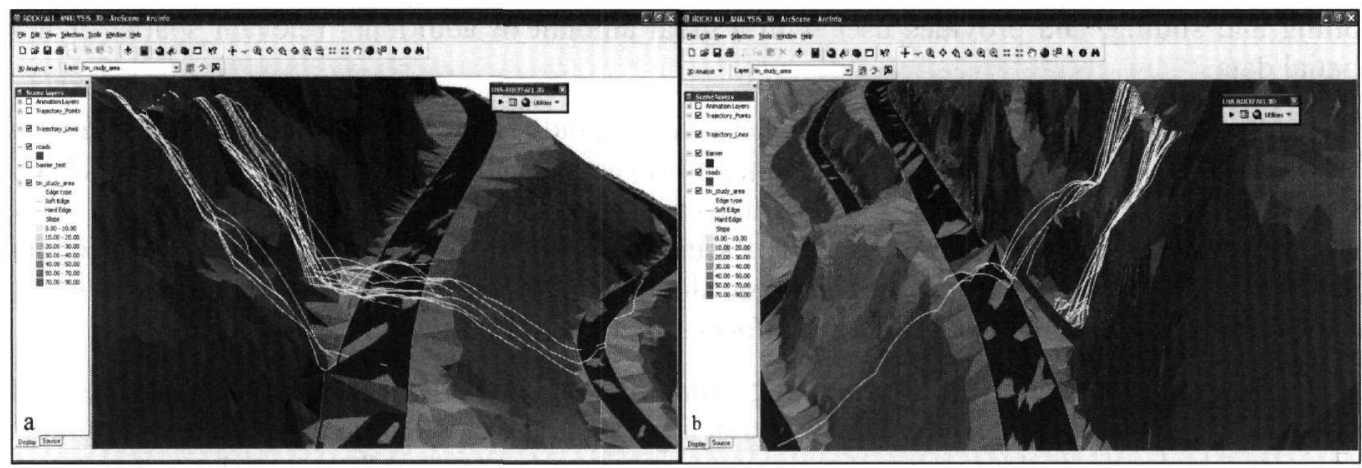

Figure 4 - a. Rockfall simulations in the case where a barrier is not used. b. Rockfall simulations in the case where a barrier is evaluated as a countermeasure

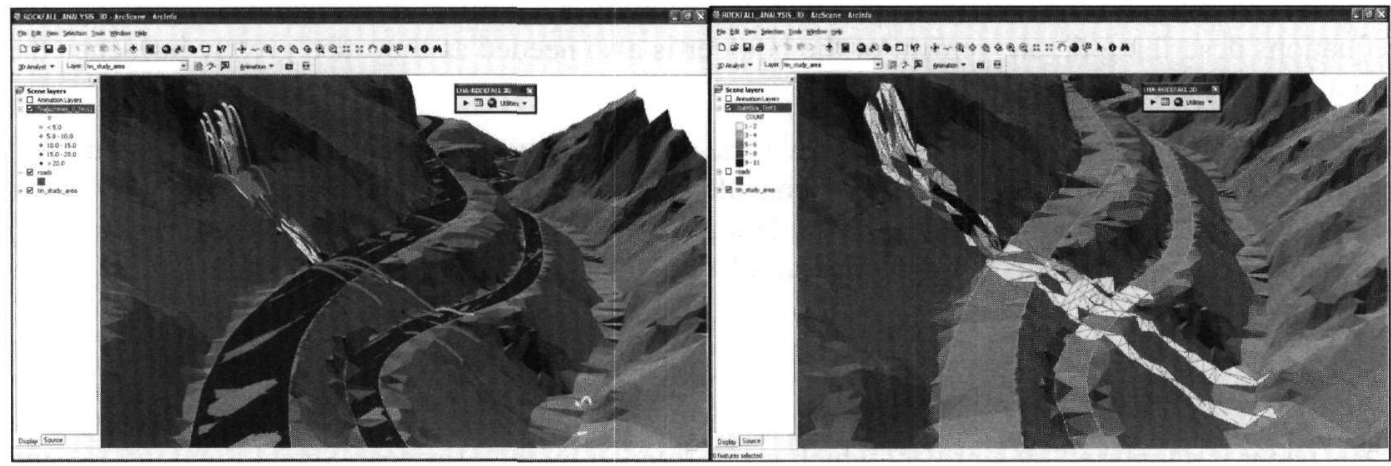

Figure 5 - a. The symbology of rockfalls based on the velocity rock boulders have along their trajectory. $b$. The subarea subjected to the simulated rockfalls. The triangles are symbolized based on the number or rockfalls traversing each triangle

As we mentioned before, statistic data for the rockfalls can be shown in tables. From just viewing these tables, engineers can find out which rockfall was the longest or the shortest, which rockfall had the biggest or the smallest duration, which rockfall had the greatest or the lowest velocity and where, and much more, information quite useful in rockfall hazard assessment. 


\section{Case Studies}

Various case studies where analyzed in order to evaluate the application ROCKFALL ANALYSIS and, consequently, the proposed simulation model (Kefalas 2006, Charalambous 2006). One of them refers to a particularly intriguing area, the Selinari area in Crete (Kefalas 2006), where a section of the new national road Herakleion - Agios Georgios of Selinari is very often subjected to rockfalls and landlsides, resulting in road destructions and in a limited road safety. A number of rockfall model simulation tests were carried out and a sample of the rockfalls tests conducted for Selinari is shown in $2 \mathrm{D}$ and in $3 \mathrm{D}$, in all the Figures of the present paper.

\section{Discussion And Conclusions}

A new 3D rockfall simulation mode is developed and incorporated in a GIS environment via the creation of the application ROCKFALL ANALYSIS. This application simulates numerous spatially distributed 3D rockfall trajectories, considering the states of bouncing (impact), free fall, rolling and sliding, and provides user with a great amount of additional relevant spatial or nonspatial data.

Using this application in various case studies, we concluded that rockfall hazard assessment and the design of countermeasures in mountainous areas can be supported by ROCKFALL ANALYSIS in a reliable way. It offers the capability of locating within an area the slopes requiring a more detailed rockfall hazard assessment. Furthermore, it is suited to ascertain rockfall hazard over both small areas (e.g. a man-made slope) and large areas, such as an entire province or a river basin, for which detailed thematic information may not be available.

Of course, this application is an on going computational tool and developments are certainly possible. While the user-interface can always be improved, the calculation aspect of the program is the one which must draw our attention. More extended probabilistic analysis has to be implemented as it is proven that employing probability and statistics in the analysis of rockfalls is an effective and acceptable method for overcoming difficulties caused by the great uncertainty which characterize the relevant parameters. Moreover, further investigation regarding the equations describing the movement of the boulder is also needed as they also greatly influence the quality of the simulations.

More radical improvements might involve the implementation of a more dynamic simulation model. At first stage, the model might consider a simple shape for the boulder (a sphere or a cylinder) allowing for a more realistic simulation of the rebound and rolling phases of rockfalls. In a second stage a complete 3D dynamic simulation of a boulder of any shape and size could be implemented.

\section{Acknowledgments}

This paper is supported by a project which is co - funded by the European Social Fund (75\%) and National Resources (25\%) - Operational Program for Educational and Vocational Training II (EPEAEK II) and particularly the Program PYTHAGORAS II - ENVIRONMENT.

\section{References}

Agliardi, F., and Crosta, G.B., 2003. High resolution three-dimensional numerical modelling of rock falls, Int. Journal of Rock Mechanics \& Mining Science, 40(4), 455-471.

Azzoni, A., La Barbera, G., and Zaninetti, A., 1995. Analysis and prediction of rock falls using a mathematical model, Int. Journal of Rock Mechanics \& Mining Science, Geomech Abstr., 32(7), 709-24. 
Badger, T.C., and Lowell, S., 1992. Rockfall Control Washington State. In Rockfall Predictionand Control and Landslide Case Histories, Transportation Research Record, National Research Council, Washington, No 1342, 14-19.

Broili, L., 1973. In situ tests for the study of rockfall, Geologia Applicata e Idrogeologia, 8 (1), 105-111. (in Italian)

Burrough, P.A., and McDonnel, R., 1998. Principles of Geographical Information Systems, University Press, Oxford.

Charalambous, S., 2006, Programming the wedge failure mode and rock fall in a GIS environment, Master Thesis, National Technical University of Athens, Athens. (in Greek)

Chau, K.T., Wong, R.H.C., and Wu, J.J., 2002. Coefficient of restitution and rotational motions of rockfall impacts, Int. Journal of Rock Mechanics \& Mining Science, 39, 69-77.

Crosta, G.B., and Agliardi, F., 2004. Parametric evaluation of 3D dispersion of rockfall trajectories, Natural Hazards and Earth System Sciences, 4, 583-598.

Crosta, G.B., and Locatelli, C., 1999. Approccio alla valutazione del rischio da frane per crollo. In Studi geografici e geologici in onore di Severino Belloni, Genova: Glauco Brigatti, 25986pp. (in Italian).

Evans, S.G., and Hungr, O., 1993. The assessment of rockfall hazard at the base of talus slopes", Can. Geotech. J., 30, 620-636.

Ferentinou, M., 2004. Landslide hazard assessment using artificial neural networks in a Geographical Information System, PhD Thesis, National Technical University of Athens. (in Greek)

Guzzetti, F., Crosta, G.B., Detti, R., and Agliardi, F., 2002. STONE: a computer program for the three- dimensional simulation of rockfalls, Computers and Geosciences, 28 (9), 10811095.

Hoek, E., 1998. Rock Engineering - The application of Modern Techniques to Underground Design, Notes from a short course by Dr Evert Hoek, Kochen \& Cella, Brazil. (also available from http:www.rocscience.com)

Jones, C.L., Higgins, J.D., and Andrew, R.D., 2000. Colorado Rock fall Simulation Program Version 4.0, Colorado Department of Transportation, Colorado Geological Survey, 127pp.

Kefalas, G., 2006. Rock fall Hazard Estimation in GIS Environment - Application in North road axis of Crete, Diploma Thesis, National Technical University, Athens. (in Greek)

Koukis, G., 1988, Slope deformation phenomena related to engineering geological conditions in Greece, Proc. of 5th Int. Symp. on Landslides, 1187-1192.

Pfeiffer, T., and Bowen, T., 1989. Computer simulation of rock falls", Bull. Assoc. Eng. Geol., 26(1), 135-46.

Ritchie, A.M., 1963. Evaluation of rock fall, its control, HRB, Highway Research Record, 17, 1328.

Rochet, L., 1987. Application des modeles numeriques de propagation a l'etude des eboulements rocheux, Bulletin des Laboratoire des Ponts et Chaussees, 150/151, 84-95. (in French)

Sakellariou, M., and Ferentinou, M., 2001. GIS-based Estimation of Slope Stability, Natural Hazards Review (ASCE), 2(1), 12-21 
Sakellariou, M., Ferentinou, M., and Charalambous, S., 2006. An Integrated GIS Tool for Seismic Induced Landslide Hazard Mapping, Proc. of $1^{\text {st }}$ European Conference on Earthquake Engineering and Seismology, Geneva, 349pp.

Varnes, D.J., 1978. Slope movement Types and Processes, In Special Report 176: Landslides: Analysis and Control (R.L. Schuster and R.. Kriezek), TRB, National Research Council, Washington D.C., 11-33. 